\title{
Predictors of Return to Work for Occupational Rehabilitation Users in Work- Related Injury Insurance Claims: Insights from Mental Health
}

\author{
Hadi Akbarzadeh Khorshidi ${ }^{1,2 *}$, Miriam Marembo ${ }^{3}$, Uwe Aickelin ${ }^{1}$ \\ ${ }^{1}$ School of Computing and Information Systems, The University of Melbourne, Melbourne, Australia \\ ${ }^{2}$ Institute for Safety Compensation and Recovery Research, Monash University, Melbourne, Australia \\ ${ }^{3}$ University Planning and Statistics, Monash University, Melbourne, Australia \\ *Email: hadi.khorshidi@unimelb.edu.au, Tel: +61390353285
}

\begin{abstract}
Purpose This study evaluates the Occupational Rehabilitation (OR) initiatives regarding return to work (RTW) and sustaining at work following work-related injuries. This study also identifies the predictors and predicts the likelihoods of RTW and sustainability for OR users. Methods The study is conducted on the compensation claim data for people who are injured at work in the state of Victoria, Australia. The claims which commenced OR services between the first of July 2012 and the end of June 2015 are included. The claims which used original employer services (OES) have been separated from claims which used new employer services (NES). We investigated a range of predictors categorised into four groups as claimant, injury, and employment characteristics and claim management. The RTW and sustaining at work are outcomes of interest. To evaluate the predictors, we use Chi-squared test and logistic regression modelling. Also, we prioritized the predictors using Akaike Information Criterion (AIC) measure and Cross-validation error. Four predictive models are developed using significant predictors for OES and NES users to predict RTW and sustainability. We examined the multicollinearity of the developed models using Variance Inflation Factor (VIF). Results About $75 \%$ and $60 \%$ of OES users achieved RTW and have been sustained at work respectively, whilst just approximately $30 \%$ of NES users have been placed at a new employer and $25 \%$ of them have been sustained at work. The predictors which have the most association with OES and NES outcomes are the use of psychiatric services and age groups respectively. We found that having mental conditions is as an important indicator to allocate injured workers into OES or NES initiatives. Our study shows that injured workers with mental issues do not always have lower RTW rate. They just need special consideration. Conclusion Understanding the predictors of RTW and sustainability helps to develop interventions to ensure sustained RTW. This study will assist decision makers to improve design and implementation of OR services and tailor services according to clients' needs.
\end{abstract}

Keywords

Occupational Rehabilitation, Return to Work, Mental Health, Workers' Compensation, Injuries 


\section{Introduction}

Injuries and illnesses that occur at work impose substantial personal, social and economic burdens on society [1]. These injuries may lead to disability, morbidity or even mortality. Many injured workers might have long-term healthcare issues. As such, return to work (RTW) for these workers becomes quite complicated. The longer the injured workers are away from work, the lower the likelihood of a successful RTW [2]. Various factors such as physical, psychological and social factors influence the process of RTW. Five stages have been identified for an injured worker to be ready for RTW in the 'Readiness for Return to Work' (RRTW) model. These stages, which are aligned with stages of change, are precontemplation, contemplation, preparation for action, action and maintenance [3, 4]. In the precontemplation stage, the injured worker has not started to think about RTW because the recovery is the priority. In the contemplation stage, as the injured worker is recovering, they are starting to consider RTW, but are not engaged in any practical plans for RTW. The preparation for action stage involves finding information regarding RTW, evaluating the capability of RTW, making plans and involvement in assistive programs to RTW. In the action stage, the injured worker converts the plan into action and gets back to work with different levels of capacity. The goal of the maintenance stage is to retain the returned injured workers at work. To reach this goal, some strategies such as receiving support from assistive programs, increasing the workload gradually, applying specific safety policies and strengthening exercise can be considered [5].

The proportion of RTW is commonly used as a measure to evaluate the success of an injury intervention program and functional recovery $[2,6]$. However, there are many instances where injured workers could not be retained at their work after RTW [7]. Therefore, the sustainability ratio is also an important measure [8]. There are several factors that are associated with the success of RTW intervention programs and recovery. In this study, we consider the last two stages of the RRTW model i.e. action and maintenance, as the desired outcomes. We investigate how preparation for RTW via occupational rehabilitation (OR) contributes to the desired RTW outcomes and which factors are highly associated with these outcomes. OR, also referred to as vocational rehabilitation or workplace rehabilitation, is a group of activities and interventions which aim to facilitate RTW.

In Victoria State, Australia, WorkSafe Victoria (WSV) is one of the state's accident compensation schemes that contributes towards healthcare and compensation of injured workers. Established in the mid-1980s, WSV provides no-fault compensation for medical and rehabilitation expenses, as well as weekly compensation to eligible workers who have had work-related injury or disease. Nearly $85 \%$ of Victoria's workforce are insured through Worksafe. The remaining $15 \%$ of the workforce comprises of Victorian workers who are sole traders, those who work for self-insuring agencies or federal government employees [9].

OR is a key component of WSV's compensation scheme. The purpose of OR is to facilitate getting back to work at a level of work activity that is appropriate to an injured worker's functional and cognitive capacities. OR services include worksite assessments and management, occupational therapy, workplace visits, vocational guidance, occupational health services, work hardening, work modification and adjustments, job accommodation, work restoration plans and ergonomics [10].

These services are provided via two initiatives as original employer services (OES) and new employer services (NES). In OES, the injured workers are prepared to get back to work with their previous employer. However, some injured workers cannot get back to their previous work. For example, a truck driver, who lost their leg due to an injury, may not be able to drive again. So, these injured workers receive NES services to learn new skills for RTW.

The performance of OR initiatives after work-related injuries has received little attention in research studies. The data from compensation claims of OR users has not been used. There have been studies on OR such as [11, 12]. However, they used survey data in their studies. In this study, we evaluate OR services regarding both RTW and sustainability for injured workers who accessed initiatives from compensation claim data, to provide a better understanding of the current situation of WSV. To provide a comprehensive evaluation, we investigate the claims' characteristics across four groups such as claimant, injury, employment and claim administration. We identify the factors associated with the likelihood of getting back to work and sustaining at work. We develop predictive models to determine how likely an injured worker is to RTW. This is aimed at assisting the identification of injured workers who need more support. This will assist WSV in tailoring their services to match client needs. In addition, the study's results provide an opportunity for decision makers to improve design and implementation of OR services. 


\section{Methods}

Data

The data we use is from the Compensation Research Database (CRD), held by the Institute for Safety, Compensation and Recovery Research (ISCRR). The CRD is an administrative database which includes the details of all claims, payments, services, hospital admissions and medical certificates for WSV and the Traffic Accident Commission (TAC) since 1985. In the CRD, there are more than 2 million claims, 70 million payment transactions, 90 million service records, 10 million medical certificates and half a million hospital admissions. Also, this database is fully deidentified and has been used in several prior injury-related studies [9]. For normalisation purposes, claims selected for this analysis include:

- Claims that had at least one day of wage compensation payment (standard time loss claims) and used OR initiatives,

- Claims which commenced OR services between the 1st of July 2012 and the 30th of June 2015,

- To ensure consistency in outcomes delivery, the follow up period was restricted to 12 months for each claim,

- Claims which used either OES or NES have been separated into two data sets ${ }^{1}$,

- Claims that had multiple commencements in OR initiatives (less than 4 percent of total claims in each data set) were removed from the data sets.

We should mention that the manuscript complies with TIPOD statement [13] using TRIPOD checklist (the checklist can be found in Appendix section).

Outcomes

RTW

This variable shows whether the OR user had been placed at work, which is aligned with stage 4 of RRTW model. The RTW variable had two values "Y" and "N" ("Y" means that a claimant was placed at work within the one-year after commencement, otherwise the value is "N").

Sustainability

This variable shows whether the OR service user had sustained RTW, which refers to stage 5 of RRTW model. We generate a binary variable where "Y" means a claimant had sustained RTW for 13 weeks and "N" otherwise.

\section{Predictors}

A range of claims' and claimants' characteristics have been selected as predictors. These characteristics are broadly categorised into claimant characteristics, injury characteristics, employment characteristics and claim management factors.

\section{Claimant characteristics}

This group includes gender and age. Gender is a categorical variable with two categories: female and male. The age of injured workers is categorised as follows: 15-24 years, 25-34 years, 35-44 years, 45-54 years, 55-64 years and others. The age groups are aligned with the relevant studies derived from the same database $[8,14]$. The reason that age groups have been used rather than the single age values is that the information in age groups are more reliable.

\section{Injury characteristics}

This group includes injury type, bodily location, cause of injury, psychiatric service utilisation and hospital admission. Injury type has seven categories: fractures, wounds, joints, musculoskeletal, mental, other injuries and other diseases. Bodily location is categorised as follows: limbs, head-neck, mental, trunk and multiple. The cause of injury has five categories: hit (hitting objects or hit by moving objects), body stress, falls, mental and others. Psychiatric service utilisation is represented by a binary variable, distinguishing workers who used psychiatric or psychology services as part of their medical procedure from those who did not use these services. Hospital admission is used as a proxy for the severity of injury, based on the number of days that an injured worker stayed in hospital. We generate five categories for this variable; "Non" for someone who was not admitted to hospital, "0-2" for injured workers who were admitted to hospital for 0 to 2 days before commencement, "3-10" for injured workers who were admitted in hospital

\footnotetext{
${ }^{1}$ We investigated the data for injured patients who used NES after OES as well. However, we did not include that investigation in this paper due to having similar results with NES users.
} 
for 3 to 10 days before commencement, "11-inf" for injured workers who were admitted for more than 11 days to hospital before commencement, and "After" for injured workers whose first hospital admission was after their commencement.

\section{Employment characteristics}

This group includes occupation groups, industry types and employer size. For occupation groups, we keep the nine WSV-defined categories. We categorise the workplace where the injury was occurred into three categories of blue collar, white collar and others as the industry type variable. The blue-collar category includes agriculture, forestry and fishing, mining, manufacturing, electricity, gas, water and waste services, construction, wholesale and retail trade, accommodation and food services, and transport postal and warehousing industries. The white-collar category includes information media and telecommunications, financial and insurance services, rental hiring and real estate, professional scientific and technical services, administrations, public administration and safety, education and training, health care and social assistance, arts and recreation services. There are three levels for employer size: small, medium and large. Governmental employers are denoted as large employers.

\section{Claim management}

This group includes the variables which are involved in claim administration: original agents, OR providers and time to OES or NES commencement. Original agents are the first agents with which the injury case is lodged. Original agents include five categories as D, H, I, L, U which are de-identified in CRD. Since the number of providers which provide OR services for injured workers in the data set is high (around 30 providers), we selected the top-six providers, accounting for more than 75 percent of workers in total and named the rest as "Others". Time to commencement (TTC) is the number of days between the claim lodgement date and the OR commencement date. This variable is the only non-categorical (quantitative) predictor.

Analysis

Various data analyse approaches have been undertaken to investigate the relationship between predictors and outcomes. Descriptive statistics were used to study RTW and sustainability shares of each predictor variable.

To determine the association between predictors and the likelihood of having particular outcomes, logistic regression analysis and the Chi-squared test (for categorical predictors) were used. Both Chi-square test and logistic regression analysis can examine whether the relationship between predictors and achieving the outcomes is significant. The level of significance is set as $5 \%$ which is examined by P-value. In addition, logistic regression was used to evaluate the strength of each predictor in determining RTW and sustainability outcomes. We use two measures, Akaike Information Criterion (AIC) and Cross-validation, to demonstrate the predictability power.

The AIC is a relative quality measure for statistical models to make a comparison with other models. It provides a balance between goodness of fit and complexity of the model. The lower the AIC value, the better the statistical model.

Cross-validation is an experimental design technique as an internal validity measure [15] to assess the prediction performance of predictive models. In 10-fold cross-validation, the data set is divided into 10 non-overlapping groups (folds). Nine groups are used to generate the model, and the remaining one is used as a validation set to measure the error between prediction and actual values (in this study, how well the logistic regression model predicts the claim outcomes in comparison with the outcomes that were observed). The procedure repeats 10 times. The average error of repetitions is used as a 10 -fold cross-validation measure. The lower the cross-validation measure, the better the model $[16,17]$.

Once significant predictors are identified, we include them into multivariate logistic regression models to predict the likelihood of RTW or sustainable RTW. Then, the predictors, which do not increase the predictability of the multivariate models, are removed in a backward method. The best multivariate model is selected based on prediction performance. Furthermore, we examine the multicollinearity among predictors in each model using Variance Inflation Factor (VIF). We remove the predictors which lead to multicollinearity.

\section{Results}

This section presents the results of separate analyses on OES and NES' RTW and sustainability outcomes. 


\section{Descriptive statistics for outcomes and predictors}

The data for OES users includes 13,474 claims, from which 9,964 had been placed at work (73.95\%) and 7,876 had sustained RTW (58.45\%). For NES users, the data includes 2,524 claims from which 766 had been placed at work (30.35\%) and 640 had sustained RTW (25.36\%).

Table 1 summarises the number of injured workers, who commenced OR services from the first of July 2012 to the end of June 2015, grouped by the predictors. Also, this table shows the percentage of RTW and sustainability among the injured workers in each category. All percentages are out of the total population. For example, $75.4 \%$ of 8343 males had RTW via OES, and 59.6\% of 8343 males had a sustained RTW via OES.

Table 1. Distribution of factors associated with RTW and sustainable RTW

\begin{tabular}{|c|c|c|c|c|c|c|}
\hline \multirow[t]{2}{*}{ Predictors } & \multicolumn{3}{|l|}{ OES } & \multicolumn{3}{|l|}{ NES } \\
\hline & $\mathrm{n}$ & $\%$ RTW & $\%$ sustainability & $\mathrm{n}$ & $\%$ RTW & $\%$ sustainability \\
\hline \multicolumn{7}{|c|}{ Claimant characteristics } \\
\hline \multicolumn{7}{|c|}{ Gender } \\
\hline Male & 8,343 & 75.4 & 59.6 & 1,563 & 29.7 & 24.5 \\
\hline Female & 5,131 & 71.6 & 56.5 & 961 & 31.4 & 26.7 \\
\hline \multicolumn{7}{|l|}{ Age groups } \\
\hline $15-24$ & 1,093 & 79.3 & 61.0 & 147 & 43.5 & 37.4 \\
\hline $25-34$ & 2,433 & 73.5 & 56.6 & 368 & 43.5 & 37.5 \\
\hline $35-44$ & 3,105 & 71.1 & 55.1 & 633 & 34.6 & 29.1 \\
\hline $45-54$ & 3,871 & 72.6 & 59.2 & 815 & 27.5 & 22.6 \\
\hline $55-64$ & 2,666 & 76.9 & 61.6 & 528 & 18.4 & 14.8 \\
\hline Others & 306 & 78.1 & 59.8 & 33 & 6.1 & 3.0 \\
\hline \multicolumn{7}{|c|}{ Injury characteristics } \\
\hline \multicolumn{7}{|c|}{ Injury type } \\
\hline Fractures & 1,691 & 83.6 & 71.0 & 166 & 28.3 & 25.3 \\
\hline Joints & 2,513 & 79.9 & 66.1 & 402 & 32.1 & 26.8 \\
\hline Mental & 1,424 & 51.6 & 35.2 & 369 & 40.4 & 32.0 \\
\hline Musculoskeletal & 5,823 & 72.2 & 55.2 & 1,245 & 27.6 & 23.0 \\
\hline Wounds & 1,194 & 80.8 & 66.7 & 170 & 26.5 & 21.8 \\
\hline Other injuries & 357 & 70.6 & 49.0 & 73 & 23.3 & 19.2 \\
\hline Other diseases & 472 & 81.4 & 69.3 & 99 & 36.4 & 34.3 \\
\hline \multicolumn{7}{|l|}{ Bodily location } \\
\hline Limbs & 7,476 & 80.0 & 67.5 & 1,248 & 30.3 & 25.9 \\
\hline Head-Neck & 576 & 72.7 & 52.6 & 143 & 23.1 & 18.2 \\
\hline Trunk & 3,522 & 70.7 & 50.7 & 665 & 26.3 & 22.1 \\
\hline Mental & 1,424 & 51.6 & 35.2 & 369 & 40.4 & 32.0 \\
\hline Multiple & 441 & 71.0 & 50.6 & 87 & 31.0 & 26.4 \\
\hline Others & 35 & 71.4 & 54.3 & 12 & 33.3 & 25.0 \\
\hline \multicolumn{7}{|l|}{ Cause of injury } \\
\hline Mental & 1,299 & 50.8 & 34.8 & 338 & 41.1 & 33.1 \\
\hline Hit & 1,768 & 79.8 & 64.7 & 227 & 38.3 & 33.0 \\
\hline Body stress & 6,026 & 73.6 & 57.4 & 1,277 & 27.4 & 23.1 \\
\hline Falls & 3,388 & 79.7 & 66.4 & 507 & 26.8 & 22.5 \\
\hline Others & 993 & 76.5 & 57.5 & 175 & 30.9 & 25.1 \\
\hline Psychiatric & & & & & & \\
\hline
\end{tabular}




\begin{tabular}{|c|c|c|c|c|c|c|}
\hline Non-user & $\begin{array}{l}10,65 \\
4\end{array}$ & 79.2 & 67.0 & 1,595 & 33.0 & 27.6 \\
\hline User & 2,820 & 54.2 & 26.1 & 929 & 25.8 & 21.4 \\
\hline \multicolumn{7}{|l|}{ Hospital admission } \\
\hline Non & 6,822 & 70.3 & 56.5 & 1,193 & 32.2 & 27.1 \\
\hline After & 1,913 & 67.0 & 41.5 & 253 & 22.9 & 20.1 \\
\hline $0-2$ & 3,469 & 82.9 & 71.3 & 704 & 32.2 & 26.8 \\
\hline $3-10$ & 918 & 80.3 & 61.9 & 226 & 26.1 & 20.8 \\
\hline 11-inf & 352 & 77.0 & 52.8 & 148 & 23.6 & 18.9 \\
\hline \multicolumn{7}{|l|}{ Employment characteristics } \\
\hline \multicolumn{7}{|l|}{ Occupation groups } \\
\hline Managers & 576 & 65.1 & 50.7 & 127 & 37.0 & 31.5 \\
\hline Professionals & 1,389 & 73.1 & 61.3 & 246 & 40.2 & 36.6 \\
\hline Associate professionals & 929 & 70.2 & 55.1 & 226 & 37.2 & 31.0 \\
\hline Tradespersons & 2,580 & 78.9 & 64.0 & 446 & 34.8 & 28.7 \\
\hline Advanced clerical and Service workers & 234 & 68.8 & 51.3 & 30 & 43.3 & 28.7 \\
\hline $\begin{array}{l}\text { Intermediate clerical, sales and Service } \\
\text { workers }\end{array}$ & 1,752 & 72.7 & 59.6 & 300 & 29.7 & 25.7 \\
\hline $\begin{array}{l}\text { Intermediate production and transport } \\
\text { workers }\end{array}$ & 2,529 & 73.1 & 57.5 & 499 & 23.4 & 18.4 \\
\hline $\begin{array}{l}\text { Elementary clerical, sales and Service } \\
\text { workers }\end{array}$ & 583 & 75.3 & 53.7 & 103 & 29.1 & 26.2 \\
\hline Labourers & 2,902 & 74.6 & 56.5 & 547 & 24.1 & 19.4 \\
\hline \multicolumn{7}{|l|}{ Industry types } \\
\hline Blue collar & 8,460 & 74.3 & 58.3 & 1,564 & 28.3 & 23.4 \\
\hline White collar & 4,575 & 73.4 & 59.2 & 885 & 33.4 & 24.8 \\
\hline Others & 439 & 73.3 & 52.6 & 75 & 37.3 & 23.7 \\
\hline \multicolumn{7}{|l|}{ Employer size } \\
\hline Small & 4,600 & 76.8 & 57.8 & 810 & 33.0 & 27.7 \\
\hline Medium & 5,872 & 72.9 & 57.6 & 921 & 28.8 & 24.8 \\
\hline Large & 3,002 & 71.8 & 61.2 & 793 & 29.5 & 23.7 \\
\hline \multicolumn{7}{|l|}{ Claim management factors } \\
\hline \multicolumn{7}{|l|}{ Original agents } \\
\hline $\mathrm{H}$ & 1,780 & 76.6 & 61.1 & 392 & 36.0 & 31.6 \\
\hline $\mathrm{D}$ & 4,114 & 75.0 & 60.8 & 628 & 31.7 & 27.1 \\
\hline I & 2,589 & 72.0 & 55.6 & 559 & 29.5 & 24.2 \\
\hline $\mathrm{L}$ & 2,863 & 71.3 & 57.4 & 500 & 29.2 & 25.4 \\
\hline U & 2,117 & 74.5 & 56.6 & 407 & 23.1 & 20.0 \\
\hline \multicolumn{7}{|l|}{ Providers } \\
\hline Others & 3,256 & 68.6 & 55.0 & 469 & 32.5 & 27.5 \\
\hline $\mathrm{C}$ & 574 & 74.2 & 57.1 & 104 & 31.7 & 30.8 \\
\hline G & 842 & 81.5 & 57.0 & 276 & 28.6 & 25.0 \\
\hline A & 964 & 71.7 & 54.7 & 233 & 36.5 & 28.8 \\
\hline $\mathrm{F}$ & 1,311 & 74.5 & 58.8 & 206 & 33.5 & 29.1 \\
\hline B & 3,122 & 75.9 & 61.7 & 562 & 31.7 & 26.5 \\
\hline $\mathrm{D}$ & 3,405 & 75.8 & 60.3 & 666 & 25.1 & 19.8 \\
\hline
\end{tabular}


Descriptive statistics show that the percentage of the sustainability is noticeably less than the percentage of RTW in all categories. That is why that being sustained at work is a crucial measure and needs a special consideration.

Significant factors associated with RTW

In this section, the results of the investigation on the relationship between predictors and RTW for injured workers who used OES or NES services are outlined. The predictors are ranked based on their power to predict RTW accurately via univariate logistic regression models. We used AIC and cross-validation measures to prioritise the predictors. Figure 1 shows how predictors are ranked to predict RTW likelihoods for OES users.

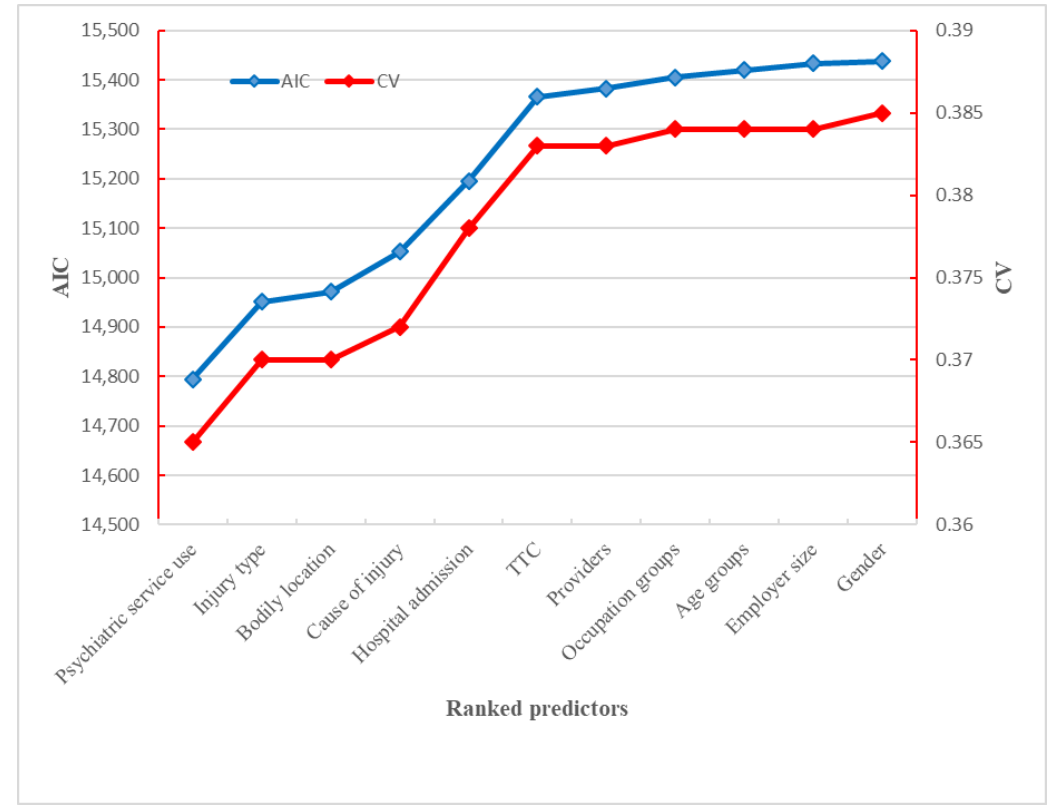

Figure 1. Ranked significant factors to predict RTW for OES users (the lower the better)

Use of psychiatric services is the most powerful predictor for RTW and gender is the least powerful one. The ranking of predictors to predict the likelihood of the RTW for NES users is presented in Figure 2.

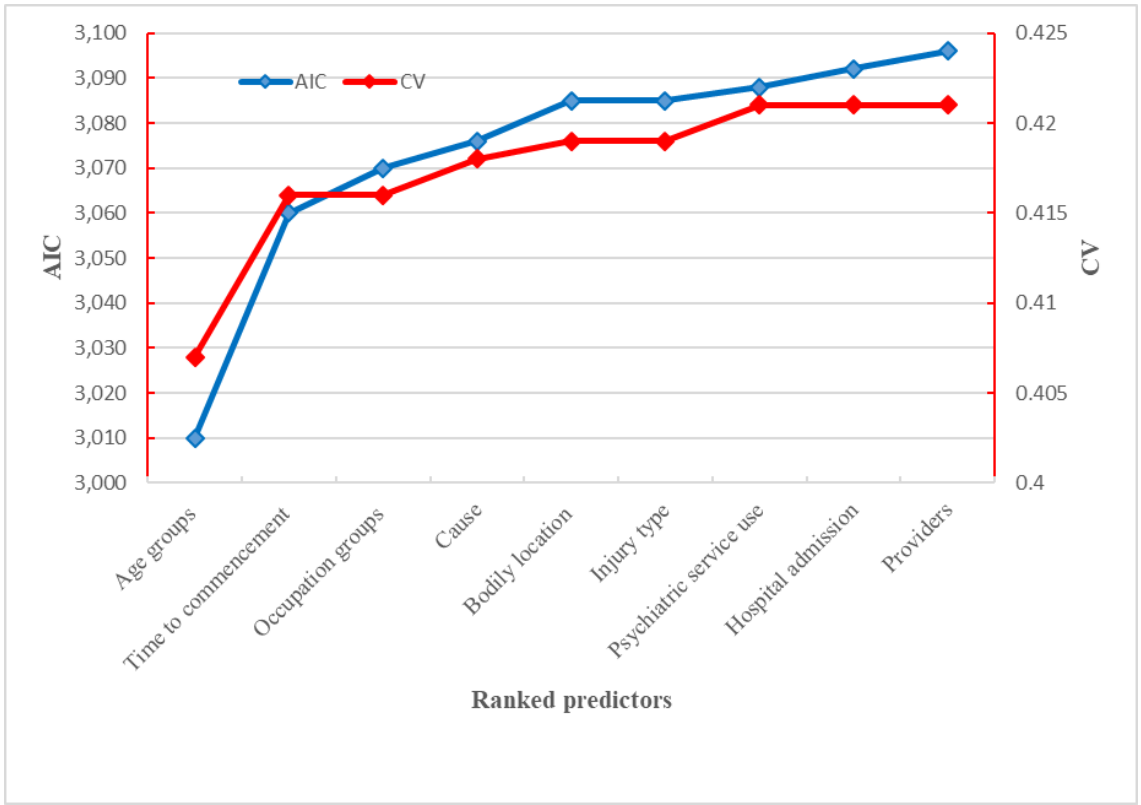

Figure 2. Ranked significant factors to predict RTW for NES users (the lower the better) 
The age of injured workers and OR service providers are respectively the most and the least powerful predictors for RTW for NES users.

Table 2 presents the outputs of univariate and multivariate logistic regression analyses on RTW for OES and NES users. In the outputs, odds ratio shows the division of the probability of success (e.g. getting RTW) over the probability of failure (e.g. not getting RTW) for each category in comparison with the reference category (Ref). So, the odds ratio for the reference category is one. An odds ratio greater (or less) than one indicates higher (or lower) odds of having success compared with the reference category. For example, female injured workers have lower likelihoods to achieve RTW compared to male category (Ref). Also, if the $95 \%$ confidence interval of odds ratio for a category does not contain one, the category has a significant impact on achieving the outcome of interest.

Table 2. Logistic regression results for factors associated with RTW via OES and NES

\begin{tabular}{|c|c|c|c|c|c|c|c|c|}
\hline & \multicolumn{2}{|c|}{$\begin{array}{l}\text { OES } \\
\text { Univariate } \\
\text { Odds }\end{array}$} & \multicolumn{2}{|c|}{$\begin{array}{l}\text { Multivariate } \\
\text { Odds }\end{array}$} & $\begin{array}{l}\text { NES } \\
\text { Univa } \\
\text { Odds } \\
\text { Ratio }\end{array}$ & $\begin{array}{l}\text { ate } \\
95 \% \mathrm{CI}\end{array}$ & $\begin{array}{l}\text { Multi } \\
\text { Odds } \\
\text { Ratio }\end{array}$ & $\begin{array}{l}\text { riate } \\
95 \% \mathrm{CI}\end{array}$ \\
\hline \multicolumn{9}{|l|}{$\begin{array}{l}\text { Claimant } \\
\text { characteristics }\end{array}$} \\
\hline \multicolumn{9}{|l|}{ Gender } \\
\hline Male & Ref & & - & & & & & \\
\hline Female & 0.826 & {$[0.763,0.893]$} & - & & & & & \\
\hline \multicolumn{9}{|l|}{ Age groups } \\
\hline $15-24$ & Ref & & Ref & & Ref & & Ref & \\
\hline $25-34$ & 0.724 & {$[0.610,0.860]$} & 0.871 & {$[0.728,1.043]$} & 0.998 & {$[0.679,1.47]$} & 1.049 & {$[0.691,1.591]$} \\
\hline $35-44$ & 0.642 & {$[0.544,0.757]$} & 0.85 & {$[0.713,1.012]$} & 0.686 & {$[0.477,0.990]$} & 0.745 & {$[0.500,1.108]$} \\
\hline $45-54$ & 0.69 & {$[0.587,0.812]$} & 0.892 & {$[0.751,1.060]$} & 0.491 & {$[0.343,0.706]$} & 0.488 & {$[0.329,0.723]$} \\
\hline $55-64$ & 0.869 & {$[0.587,0.812]$} & 1.035 & {$[0.863,1.242]$} & 0.292 & {$[0.197,0.433]$} & 0.288 & {$[0.187,0.444]$} \\
\hline $\begin{array}{l}\text { Others } \\
\text { Injury } \\
\text { characteristics }\end{array}$ & 0.93 & {$[0.587,0.812]$} & 0.925 & {$[0.671,1.276]$} & 0.084 & {$[0.013,0.291]$} & 0.054 & {$[0.007,0.410]$} \\
\hline \multicolumn{9}{|l|}{ Injury type } \\
\hline Fractures & Ref & & Ref & & Ref & & - & \\
\hline Joints & 0.777 & {$[0.661,0.913]$} & 0.835 & {$[0.704,0.990]$} & 1.196 & {$[0.808,1.791]$} & - & \\
\hline Musculoskeletal & 0.51 & {$[0.443,0.587]$} & 0.644 & {$[0.553,0.749]$} & 0.963 & {$[0.676,1.391]$} & - & \\
\hline Mental & 0.209 & {$[0.177,0.247]$} & 0.432 & {$[0.354,0.526]$} & 1.715 & {$[1.159,2.565]$} & - & \\
\hline Other Diseases & 0.855 & {$[0.656,1.114]$} & 0.836 & {$[0.635,1.102]$} & 0.911 & {$[0.563,1.473]$} & - & \\
\hline Other Injuries & 0.47 & {$[0.362,0.611]$} & 0.612 & {$[0.466,0.804]$} & 0.769 & {$[0.398,1.437]$} & - & \\
\hline Wounds & 0.826 & {$[0.680,1.001]$} & 0.851 & {$[0.696,1.040]$} & 1.447 & {$[0.849,2.459]$} & - & \\
\hline \multicolumn{9}{|l|}{ Bodily location } \\
\hline Head-Neck & Ref & & - & & Ref & & - & \\
\hline Limbs & 1.502 & {$[1.239,1.819]$} & - & & 1.448 & {$[0.975,2.206]$} & - & \\
\hline Mental & 0.4 & {$[0.324,0.494]$} & - & & 1.19 & {$[0.786,1.844]$} & - & \\
\hline Multiple & 0.916 & {$[0.696,1.207]$} & - & & 2.258 & {$[1.466,3.549]$} & - & \\
\hline Others & 0.937 & {$[0.440,1.995]$} & - & & 1.5 & {$[0.822,2.728]$} & - & \\
\hline Trunk & 0.903 & {$[0.741,1.100]$} & - & & 1.667 & {$[0.423,5.651]$} & - & \\
\hline \multicolumn{9}{|l|}{ Cause of injury } \\
\hline Body stress & Ref & & - & & Ref & & Ref & \\
\hline Falls & 1.406 & {$[1.271,1.557]$} & - & & 0.971 & {$[0.769,1.222]$} & 1.033 & {$[0.794,1.344]$} \\
\hline Hit & 1.419 & {$[1.247,1.615]$} & - & & 1.645 & {$[1.223,2.206]$} & 1.666 & {$[1.189,2.334]$} \\
\hline Mental & 0.371 & {$[0.328,0.419]$} & - & & 1.85 & {$[1.441,2.372]$} & 2.344 & {$[1.675,3.280]$} \\
\hline Others & 1.171 & {$[1.000,1.371]$} & - & & 1.182 & {$[0.833,1.658]$} & 1.205 & {$[0.813,1.787]$} \\
\hline
\end{tabular}




\begin{tabular}{|c|c|c|c|c|c|c|c|c|}
\hline \multicolumn{9}{|l|}{$\begin{array}{l}\text { Psychiatric } \\
\text { service use }\end{array}$} \\
\hline Non-user & Ref & & Ref & & Ref & & Ref & \\
\hline $\begin{array}{l}\text { User } \\
\text { Hospital } \\
\text { admission }\end{array}$ & 0.311 & {$[0.285,0.339]$} & 0.424 & {$[0.382,0.471]$} & 0.708 & {$[0.591,0.847]$} & 0.475 & {$[0.375,0.602]$} \\
\hline Non & 0.439 & {$[0.394,0.489]$} & 0.529 & {$[0.469,0.598]$} & 1.009 & {$[0.827,1.232]$} & 0.728 & {$[0.570,0.929]$} \\
\hline After & 0.373 & {$[0.326,0.427]$} & 0.435 & {$[0.376,0.503]$} & 0.625 & {$[0.445,0.867]$} & 0.357 & {$[0.237,0.538]$} \\
\hline 0-2 days & Ref & & Ref & & Ref & & Ref & \\
\hline 3-10 days & 0.678 & {$[0.569,0.808]$} & 0.802 & {$[0.667,0.965]$} & 0.742 & {$[0.527,1.034]$} & 0.947 & {$[0.651,1.379]$} \\
\hline $\begin{array}{l}\geq 11 \text { days } \\
\text { Employment } \\
\text { characteristics }\end{array}$ & 0.492 & {$[0.392,0.617]$} & 0.663 & {$[0.520,0.847]$} & 0.651 & {$[0.427,0.972]$} & 0.711 & {$[0.440,1.150]$} \\
\hline \multicolumn{9}{|l|}{ Occupation } \\
\hline Managers & Ref & & Ref & & Ref & & Ref & \\
\hline $\begin{array}{l}\text { Professionals } \\
\text { Associate } \\
\text { professionals }\end{array}$ & $\begin{array}{l}1.455 \\
1.262\end{array}$ & $\begin{array}{l}{[1.181,1.792]} \\
{[1.011,1.575]}\end{array}$ & $\begin{array}{l}1.533 \\
1.219\end{array}$ & $\begin{array}{l}{[1.222,1.924]} \\
{[0.961,1.548]}\end{array}$ & $\begin{array}{l}1.146 \\
1.007\end{array}$ & $\begin{array}{l}{[0.739,1.789]} \\
{[0.643,1.584]}\end{array}$ & $\begin{array}{l}1.272 \\
1.115\end{array}$ & $\begin{array}{l}{[0.782,2.070]} \\
{[0.682,1.823]}\end{array}$ \\
\hline $\begin{array}{l}\text { Tradespersons } \\
\text { Advanced } \\
\text { clerical \& }\end{array}$ & 2.001 & {$[1.646,2.434]$} & 1.322 & {$[1.067,1.638]$} & 0.906 & {$[0.604,1.372]$} & 0.925 & {$[0.583,1.467]$} \\
\hline $\begin{array}{l}\text { service workers } \\
\text { Intermediate } \\
\text { clerical, sales \& }\end{array}$ & 1.182 & {$[0.854,1.637]$} & 1.229 & {$[0.867,1.743]$} & 1.302 & {$[0.573,2.91]$} & 1.382 & {$[0.572,3.340]$} \\
\hline $\begin{array}{l}\text { service workers } \\
\text { Intermediate } \\
\text { production \& } \\
\text { transport }\end{array}$ & 1.424 & {$[1.165,1.742]$} & 1.292 & {$[1.039,1.605]$} & 0.718 & {$[0.465,1.115]$} & 0.767 & {$[0.473,1.244]$} \\
\hline $\begin{array}{l}\text { workers } \\
\text { Elementary } \\
\text { clerical, sales \& }\end{array}$ & 1.455 & {$[1.200,1.763]$} & 1.08 & {$[0.875,1.332]$} & 0.521 & {$[0.345,0.793]$} & 0.488 & {$[0.304,0.783]$} \\
\hline service workers & 1.634 & {$[1.267,2.108]$} & 1.389 & {$[1.059,1.823]$} & 0.7 & {$[0.398,1.217]$} & 0.679 & {$[0.365,1.264]$} \\
\hline Labourers & 1.577 & {$[1.304,1.909]$} & 1.129 & {$[0.917,1.391]$} & 0.541 & {$[0.360,0.819]$} & 0.529 & {$[0.333,0.841]$} \\
\hline \multicolumn{9}{|l|}{ Employer size } \\
\hline Large & Ref & & Ref & & & & & \\
\hline Medium & 1.055 & {$[0.956,1.164]$} & 0.872 & {$[0.780,0.975]$} & & & & \\
\hline $\begin{array}{l}\text { Small } \\
\text { Claim } \\
\text { management } \\
\text { factors }\end{array}$ & 1.298 & {$[1.169,1.442]$} & 0.823 & {$[0.726,0.932]$} & & & & \\
\hline \multicolumn{9}{|l|}{ Providers } \\
\hline $\mathrm{D}$ & Ref & & Ref & & Ref & & Ref & \\
\hline $\mathrm{F}$ & 0.934 & {$[0.806,1.082]$} & 0.899 & {$[0.771,1.049]$} & 0.863 & {$[0.531,1.417]$} & 1.379 & {$[0.939,2.025]$} \\
\hline G & 1.404 & {$[1.160,1.699]$} & 1.475 & {$[1.209,1.799]$} & 1.236 & {$[0.760,2.036]$} & 1.16 & {$[0.809,1.663]$} \\
\hline A & 0.808 & {$[0.688,0.949]$} & 0.822 & {$[0.695,0.973]$} & 1.084 & {$[0.657,1.806]$} & 1.628 & {$[1.134,2.338]$} \\
\hline B & 1.004 & {$[0.897,1.125]$} & 1.004 & {$[0.891,1.131]$} & 0.997 & {$[0.641,1.579]$} & 1.311 & {$[0.992,1.732]$} \\
\hline $\mathrm{C}$ & 0.919 & {$[0.750,1.126]$} & 0.853 & {$[0.690,1.055]$} & 0.72 & {$[0.463,1.139]$} & 1.381 & {$[0.826,2.310]$} \\
\hline Other & 0.698 & {$[0.627,0.777]$} & 0.708 & {$[0.632,0.793]$} & 1.036 & {$[0.662,1.648]$} & 1.421 & {$[1.062,1.901]$} \\
\hline \multicolumn{9}{|l|}{ TTC } \\
\hline $\mathrm{TTC}=0$ & Ref & & Ref & & Ref & & Ref & \\
\hline $\mathrm{TTC}=1$ day & 0.999 & {$[0.999,0.999]$} & 0.998 & {$[0.998,0.999]$} & 0.999 & {$[0.999,1.000]$} & 0.999 & {$[0.999,1.000]$} \\
\hline Observations & 13,474 & & & & 2,524 & & & \\
\hline
\end{tabular}

* 95\% confidence interval (95\% CI) 
We examined the severity of multicollinearity in the multivariate logistic regression models using Variance Inflation Factor (VIF). It shows that there is a high correlation between injury types, bodily location and cause of injury. Therefore, we only included the most powerful predictor amongst them in the multivariate models.

Adding gender into the multivariate logistic regression model of OES users reduces the prediction accuracy of the model. So, gender was excluded from the final model. Also, only injury type is included to prevent the multicollinearity between injury types, bodily location and cause of injury.

For OES users, the multivariate model showed injured workers in the age group of 35-44, being psychiatric service user, having hospital admission after OES commencement, with mental injury type, working in a managerial level for a small employer and commencing OES services later with none of the top-six providers had the least likelihood for a RTW.

On the other hand, injured workers in the age group of 15-24, not-using psychiatric services, having less than 2 days hospital admission, with fractures injuries, working as elementary clerical, sales and service workers for a large employer and commencing OES services earlier with one of the top-six providers had the most likelihood for RTW at the original employer.

Like the OES model, we only kept the most powerful variable (cause of injury) amongst injury type, bodily location and cause of injury due to the multicollinearity.

For NES users, the multivariate model shows injured workers in the age group of 55-64, being psychiatric service user, having hospital admission after OR commencement, with cause of injury of body stress, working as an intermediate production and transport workers and commencing NES services late by provider $\mathrm{C}$ had the least likelihood for RTW.

On the other hand, injured workers in the age group of 25-34, not-using psychiatric services, having less than 2 days hospital admission, with the injury cause of mental, working as advanced clerical and service workers and commencing NES services earlier by provider A had the most likelihood for RTW at a new employer.

\section{Significant factors associated with sustainability}

This section outlines the results of our investigation on the relationship between predictors and being sustained at work for injured workers who used OES or NES services. Figure 3 shows the order of predictors based on their power to predict sustainability likelihood for OES users.

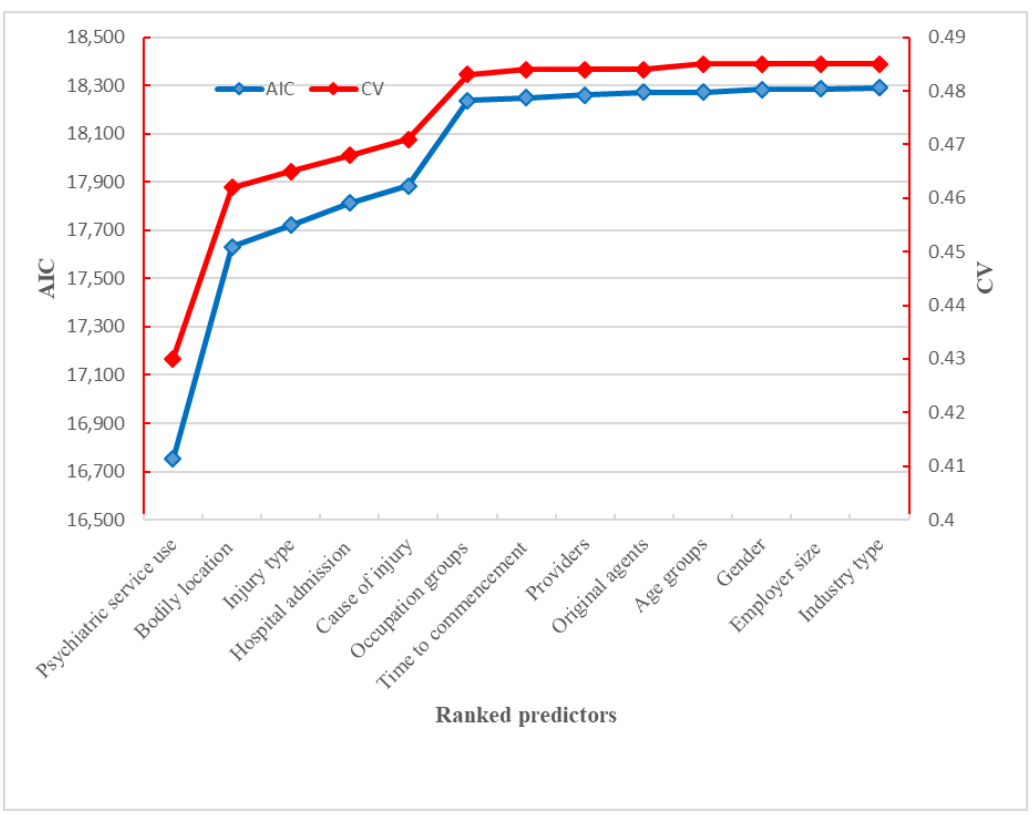

Figure 3. Ranked significant factors to predict sustainability of OES users (the lower the better) 
The most powerful predictor for OES sustainability is use of psychiatric services which consistent with the results from RTW of OES users. The least powerful predictors are age groups, gender, employer size and industry type. Figure 4 shows the order of predictors based on their power to predict sustainability likelihood for NES users.

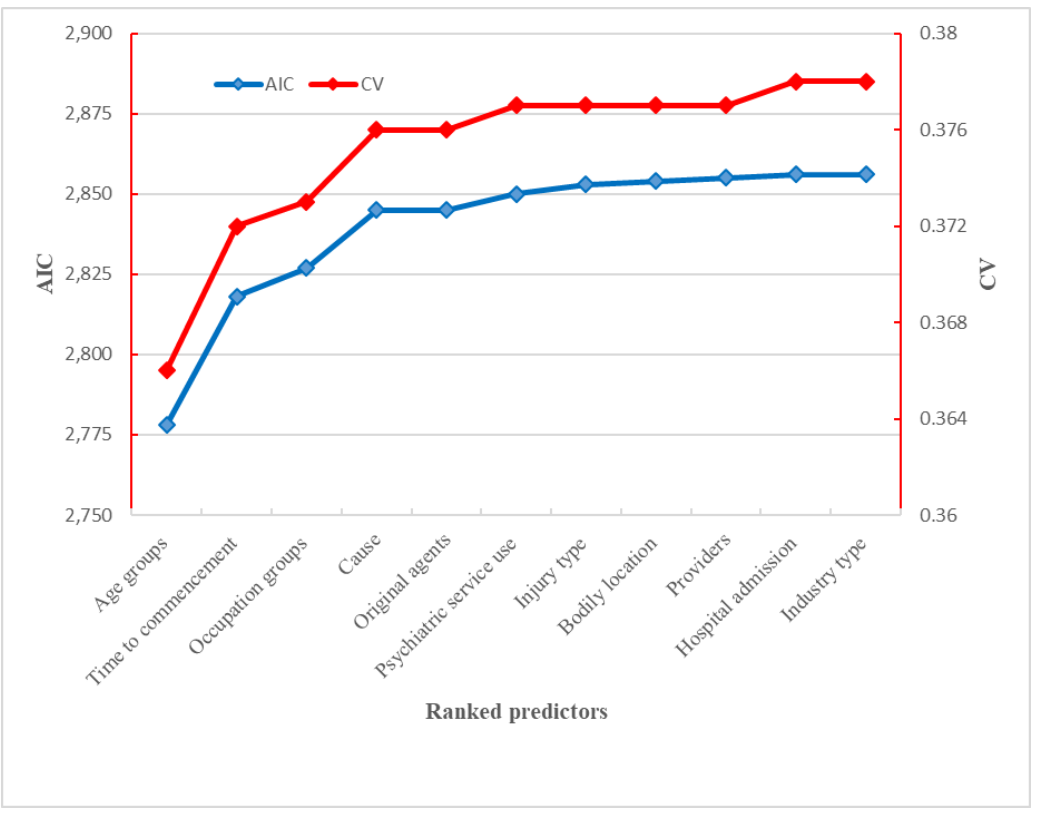

Figure 4. Ranked significant factors to predict sustainability for NES users (the lower the better)

The most powerful predictor for NES sustainability is the injured workers' age group which is aligned with the results of RTW for NES users. The least powerful predictors are hospital admission and industry type.

Table 3 presents the outputs of univariate and multivariate logistic regression models on the sustainability likelihood for OES and NES users.

Table 3. Logistic regression results of significant factors on sustainability for OES users

\begin{tabular}{|c|c|c|c|c|c|c|c|c|}
\hline & $\begin{array}{l}\text { OES } \\
\text { Univa। } \\
\text { Odds } \\
\text { Ratio } \\
\end{array}$ & $95 \% \mathrm{CI}$ & $\begin{array}{l}\text { Multi } \\
\text { Odds } \\
\text { Ratio } \\
\end{array}$ & $\begin{array}{l}\text { riate } \\
95 \% \mathrm{CI}\end{array}$ & $\begin{array}{l}\text { NES } \\
\text { Univa } \\
\text { Odds } \\
\text { Ratio }\end{array}$ & $\begin{array}{l}\text { ate } \\
95 \% \mathrm{CI}\end{array}$ & $\begin{array}{l}\text { Multiv } \\
\text { Odds } \\
\text { Ratio } \\
\end{array}$ & $\begin{array}{l}\text { riate } \\
95 \% \text { CI }\end{array}$ \\
\hline \multicolumn{9}{|l|}{$\begin{array}{l}\text { Claimant } \\
\text { characteristics }\end{array}$} \\
\hline \multicolumn{9}{|l|}{ Gender } \\
\hline Male & Ref & & Ref & & & & & \\
\hline Female & 0.879 & {$[0.819,0.943]$} & 0.864 & {$[0.784,0.951]$} & & & & \\
\hline \multicolumn{9}{|l|}{ Age groups } \\
\hline $15-24$ & Ref & & Ref & & Ref & & Ref & \\
\hline $25-34$ & 0.832 & {$[0.719,0.962]$} & 0.961 & {$[0.820,1.126]$} & 1.036 & {$[0.696,1.541]$} & 1.211 & {$[0.795,1.845]$} \\
\hline $35-44$ & 0.789 & {$[0.685,0.908]$} & 1.005 & {$[0.861,1.173]$} & 0.705 & {$[0.484,1.029]$} & 0.877 & {$[0.587,1.311]$} \\
\hline $45-54$ & 0.926 & {$[0.807,1.063]$} & 1.149 & {$[0.987,1.337]$} & 0.507 & {$[0.349,0.737]$} & 0.601 & {$[0.404,0.894]$} \\
\hline $55-64$ & 1.024 & {$[0.886,1.183]$} & 1.099 & {$[0.938,1.289]$} & 0.301 & {$[0.199,0.456]$} & 0.33 & {$[0.214,0.510]$} \\
\hline $\begin{array}{l}\text { Others } \\
\text { Injury } \\
\text { characteristics }\end{array}$ & 0.95 & {$[0.734,1.231]$} & 0.85 & {$[0.643,1.124]$} & 0.053 & {$[0.007,0.401]$} & 0.054 & {$[0.007,0.414]$} \\
\hline \multicolumn{9}{|l|}{ Injury type } \\
\hline Fractures & Ref & & - & & Ref & & - & \\
\hline Joints & 0.799 & {$[0.699,0.913]$} & - & & 1.059 & {$[0.699,1.604]$} & - & \\
\hline Musculoskeletal & 0.505 & {$[0.449,0.567]$} & - & & 0.881 & {$[0.606,1.282]$} & - & \\
\hline
\end{tabular}




\begin{tabular}{|c|c|c|c|c|c|c|c|c|}
\hline Mental & 0.222 & {$[0.191,0.258]$} & - & & 1.36 & {$[0.899,2.057]$} & - & \\
\hline Other Diseases & 0.917 & {$[0.734,1.145]$} & - & & 1.555 & {$[0.901,2.682]$} & - & \\
\hline Other Injuries & 0.393 & {$[0.312,0.496]$} & - & & 0.684 & {$[0.346,1.350]$} & - & \\
\hline Wounds & 0.818 & {$[0.697,0.960]$} & - & & 0.798 & {$[0.479,1.328]$} & - & \\
\hline \multicolumn{9}{|l|}{ Bodily location } \\
\hline Head-Neck & Ref & & Ref & & Red & & - & \\
\hline Limbs & 1.88 & {$[1.584,2.230]$} & 1.46 & {$[1.210,1.761]$} & 1.584 & {$[1.016,2.470]$} & - & \\
\hline Mental & 0.492 & {$[0.404,0.599]$} & 0.898 & {$[0.715,1.127]$} & 2.106 & {$[1.305,3.397]$} & - & \\
\hline Multiple & 0.924 & {$[0.720,1.184]$} & 0.892 & {$[0.680,1.170]$} & 1.682 & {$[0.886,3.193]$} & - & \\
\hline Others & 1.077 & {$[0.543,2.136]$} & 0.639 & {$[0.305,1.339]$} & 1.487 & {$[0.376,5.877]$} & - & \\
\hline $\begin{array}{l}\text { Trunk } \\
\text { Cause of } \\
\text { injury }\end{array}$ & 0.935 & {$[0.784,1.116]$} & 0.853 & {$[0.703,1.034]$} & 1.28 & {$[0.805,2.034]$} & - & \\
\hline Body stress & 0.53 & & - & & Ref & & Ref & \\
\hline Falls & 1.469 & {$[1.346,1.604]$} & - & & 0.963 & {$[0.751,1.234]$} & 0.948 & {$[0.727,1.235]$} \\
\hline Hit & 1.36 & {$[1.218,1.518]$} & - & & 1.627 & {$[1.198,2.210]$} & 1.74 & {$[1.249,2.423]$} \\
\hline Mental & 0.396 & {$[0.349,0.448]$} & - & & 1.63 & {$[1.255,2.118]$} & 1.842 & {$[1.317,2.577]$} \\
\hline $\begin{array}{l}\text { Others } \\
\text { Psychiatric } \\
\text { service use }\end{array}$ & 1.001 & {$[0.874,1.146]$} & - & & 1.117 & {$[0.775,1.611]$} & 1.193 & {$[0.805,1.768]$} \\
\hline Non-user & Ref & & Ref & & Ref & & Ref & \\
\hline $\begin{array}{l}\text { User } \\
\text { Hospital } \\
\text { admission }\end{array}$ & 0.174 & {$[0.158,0.191]$} & 0.189 & {$[0.168,0.211]$} & 0.721 & {$[0.595,0.873]$} & 0.545 & {$[0.432,0.687]$} \\
\hline Non & 0.456 & {$[0.416,0.500]$} & 0.588 & {$[0.528,0.656]$} & 1.028 & {$[0.832,1.269]$} & 0.755 & {$[0.591,0.965]$} \\
\hline After & 0.246 & {$[0.218,0.278]$} & 0.291 & {$[0.255,0.333]$} & 0.74 & {$[0.523,1.047]$} & 0.607 & {$[0.419,0.878]$} \\
\hline $0-2$ days & Ref & & Ref & & Ref & & Ref & \\
\hline 3-10 days & 0.502 & {$[0.434,0.580]$} & 0.656 & {$[0.560,0.767]$} & 0.743 & {$[0.517,1.069]$} & 0.824 & {$[0.559,1.214]$} \\
\hline $\begin{array}{l}\geq 11 \text { days } \\
\text { Employment } \\
\text { characteristics } \\
\text { Occupation }\end{array}$ & 0.326 & {$[0.267,0.398]$} & 0.518 & {$[0.416,0.645]$} & 0.69 & {$[0.441,1.080]$} & 0.742 & {$[0.460,1.199]$} \\
\hline Managers & Ref & & Ref & & Ref & & Ref & \\
\hline $\begin{array}{l}\text { Professionals } \\
\text { Associate }\end{array}$ & 1.537 & {$[1.263,1.869]$} & 1.408 & {$[1.121,1.769]$} & 1.296 & {$[0.821,2.046]$} & 1.371 & {$[0.846,2.220]$} \\
\hline professionals & 1.198 & {$[0.972,1.475]$} & 1.139 & {$[0.901,1.441]$} & 0.987 & {$[0.617,1.580]$} & 1.05 & {$[0.641,1.720]$} \\
\hline $\begin{array}{l}\text { Tradespersons } \\
\text { Advanced } \\
\text { clerical \& }\end{array}$ & 1.726 & {$[1.438,2.070]$} & 1.218 & {$[0.988,1.502]$} & 0.892 & {$[0.582,1.368]$} & 0.83 & {$[0.524,1.315]$} \\
\hline $\begin{array}{l}\text { service workers } \\
\text { Intermediate } \\
\text { clerical, sales \& }\end{array}$ & 1.024 & {$[0.755,1.387]$} & 0.877 & {$[0.622,1.236]$} & 1.088 & {$[0.466,2.535]$} & 1.016 & {$[0.413,2.499]$} \\
\hline $\begin{array}{l}\text { service workers } \\
\text { Intermediate } \\
\text { production \& } \\
\text { transport }\end{array}$ & 1.437 & {$[1.189,1.736]$} & 1.229 & {$[0.990,1.527]$} & 0.768 & {$[0.487,1.212]$} & 0.744 & {$[0.460,1.202]$} \\
\hline $\begin{array}{l}\text { workers } \\
\text { Elementary } \\
\text { clerical, sales \& }\end{array}$ & 1.312 & {$[1.095,1.573]$} & 0.999 & {$[0.810,1.231]$} & 0.5 & {$[0.323,0.775]$} & 0.499 & {$[0.313,0.796]$} \\
\hline service workers & 1.127 & {$[0.895,1.420]$} & 0.961 & {$[0.742,1.244]$} & 0.764 & {$[0.427,1.369]$} & 0.715 & {$[0.386,1.323]$} \\
\hline Labourers & 1.263 & {$[1.056,1.511]$} & 0.892 & {$[0.728,1.093]$} & 0.525 & {$[0.341,0.808]$} & 0.504 & {$[0.318,0.800]$} \\
\hline Industry type & & & & & & & & \\
\hline Blue collar & Ref & & Ref & & Ref & & - & \\
\hline White collar & 1.035 & {$[0.962,1.113]$} & 1.181 & {$[1.062,1.313]$} & 1.333 & {$[1.105,1.608]$} & - & \\
\hline Others & 0.793 & {$[0.654,0.961]$} & 0.748 & {$[0.604,0.926]$} & 1.248 & {$[0.735,2.118]$} & - & \\
\hline
\end{tabular}




\begin{tabular}{|c|c|c|c|c|c|c|c|c|}
\hline Large & Ref & & Ref & & & & & \\
\hline Medium & 0.861 & {$[0.787,0.942]$} & 0.737 & {$[0.661,0.823]$} & & & & \\
\hline $\begin{array}{l}\text { Small } \\
\text { Claim } \\
\text { management } \\
\text { factors } \\
\text { Original } \\
\text { agents }\end{array}$ & 0.87 & {$[0.792,0.956]$} & 0.564 & {$[0.499,0.637]$} & & & & \\
\hline $\mathrm{D}$ & Ref & & Ref & & Ref & & Ref & \\
\hline $\mathrm{H}$ & 1.012 & {$[0.903,1.134]$} & 0.955 & {$[0.841,1.085]$} & 1.247 & {$[0.946,1.643]$} & 1.24 & {$[0.919,1.672]$} \\
\hline I & 0.81 & {$[0.733,0.894]$} & 0.845 & {$[0.755,0.945]$} & 0.858 & {$[0.660,1.114]$} & 0.866 & {$[0.652,1.150]$} \\
\hline $\mathrm{L}$ & 0.867 & {$[0.787,0.956]$} & 0.957 & {$[0.856,1.069]$} & 0.917 & {$[0.702,1.199]$} & 0.854 & {$[0.639,1.142]$} \\
\hline $\mathrm{U}$ & 0.841 & {$[0.756,0.935]$} & 0.834 & {$[0.740,0.940]$} & 0.669 & {$[0.496,0.904]$} & 0.65 & {$[0.471,0.897]$} \\
\hline \multicolumn{9}{|l|}{ Providers } \\
\hline $\mathrm{D}$ & Ref & & Ref & & Ref & & Ref & \\
\hline $\mathrm{F}$ & 0.942 & {$[0.827,1.072]$} & 0.912 & {$[0.789,1.053]$} & 1.653 & {$[1.156,2.362]$} & 1.534 & {$[1.047,2.248]$} \\
\hline G & 0.874 & {$[0.751,1.019]$} & 0.896 & {$[0.757,1.061]$} & 1.326 & {$[0.950,1.850]$} & 1.444 & {$[1.015,2.055]$} \\
\hline A & 0.795 & {$[0.689,0.919]$} & 0.784 & {$[0.669,0.919]$} & 1.585 & {$[1.124,2.236]$} & 1.694 & {$[1.174,2.445]$} \\
\hline B & 1.064 & {$[0.963,1.175]$} & 1.032 & {$[0.923,1.153]$} & 1.439 & {$[1.100,1.883]$} & 1.317 & {$[0.987,1.757]$} \\
\hline $\mathrm{C}$ & 0.879 & {$[0.735,1.052]$} & 0.816 & {$[0.670,0.994]$} & 1.751 & {$[1.107,2.769]$} & 2.01 & {$[1.235,3.272]$} \\
\hline Other & 0.806 & {$[0.731,0.888]$} & 0.795 & {$[0.714,0.886]$} & 1.5 & {$[1.136,1.981]$} & 1.571 & {$[1.168,2.114]$} \\
\hline \multicolumn{9}{|l|}{ TTC } \\
\hline $\mathrm{TTC}=0$ & Ref & & Ref & & Ref & & Ref & \\
\hline TTC = 1 day & 0.999 & {$[0.999,0.999]$} & 0.999 & {$[0.999,0.999]$} & 0.999 & {$[0.999,1.000]$} & 0.999 & {$[0.999,1.000]$} \\
\hline Observations & 13,463 & & & & 2,486 & & & \\
\hline
\end{tabular}

Amongst injury types, bodily location and cause of injury, only bodily location is included in the multivariate logistic regression model for OES users to prevent the severe multicollinearity.

For OES users, the multivariate model shows that female injured workers in the age group of 25-34, being psychiatric service users, having hospital admission after OES commencement, with "other" injury types, working as advanced clerical and service workers for a small employer in a neither blue nor white collar industry, managed by agent $U$ and commencing OES services later with provider A had the least likelihood to sustain a RTW.

On the other hand, male injured workers in the age group of 45-54, not being psychiatric service users, having hospital admission for less than 2 days, with limbs injury type, working as professionals for a large employer in a white-collar industry, managed by agent D and commencing OES services early with provider B had the most likelihood for sustainability at the original employer.

In the multivariate logistic regression model, adding industry type reduces the prediction accuracy of the model. So, industry type was excluded from the final model. Also, we only kept the most powerful predictor among injury type, bodily location and cause of injury, which is cause of injury.

For NES users, the multivariate model showed injured workers in the age group of 55-64, being psychiatric service users, having hospital admission after OR commencement, with cause of injury of falling, working as intermediate production and transport workers, managed by agent $\mathrm{U}$ and commencing at NES services late by the provider D had the least likelihood of sustainability.

On the other hand, injured workers in the age group of 25-34, not-using psychiatric services, having hospital admission between 3 and 10 days, with the injury cause of mental, working as professionals, managed by agent $\mathrm{H}$ and commencing at NES services earlier by the provider $\mathrm{C}$ had the most likelihood to be sustained at a new employer.

\section{Discussion}

In this section, the key findings from analytical investigations on RTW and sustainability for both OES and NES users are discussed. Over the period of study, around 75 percent of OES service users had RTW at their original employer, 
whilst around 60 percent of them have been sustained at work. For NES users, approximately 30 percent have been placed and 25 percent have been sustained at work with a new employer. Cross-validation is used as an internal validation method. So, we can measure the performance of the substantial factors to predict RTW and sustainability for Victorian work-related injured patients.

OES

The substantial factors, which have a significant relationship with achieving OES RTW and sustainability, are psychiatric service use, injury type, bodily location, cause of injury, hospital admission, TTC, providers, occupation groups, age groups, employer size and gender in succeeding order.

The most associated factor with OES outcomes is use of psychiatric services. Injured workers who used psychiatric (or psychology) services had substantially lower likelihood to achieve RTW and sustainability in comparison with those with no psychiatric service use. The difference in sustainability likelihood between psychiatric service users and non-users was much higher than for RTW likelihood.

The injury type, bodily location and cause of injuries are other substantial factors. Regarding these three factors, the injured workers in the mental category were less likely to be returned and sustained at their original employer.

Agents did not have significant relationship with achieving RTW via OES initiative and were not a powerful factor for OES sustainability. This may demonstrate that there is a consistent and uniform approach to OR services provision among WSV's agents.

The gender and employer size were the least powerful factors on RTW and sustainability via OES.

NES

The significant factors, which have a relationship with RTW and sustainability via NES, are age groups, TTC, occupation groups, cause of injury, bodily location, hospital admission, injury type, psychiatric service use and OR providers in succeeding order.

The most associated factor with RTW and sustainability via NES is age groups. The higher the age of injured workers, the lower the likelihood to be placed and sustained at a new employer.

Other substantial factors are TTC and occupation groups. When the time between claim lodgement and NES commencement is lower, an injured worker is more likely to find a new RTW and being sustained at the new job. Within occupation groups, intermediate production and transport workers and labourers are the groups with the least likelihood of RTW and sustainability via NES.

In contrast with OES, injured workers with mental injuries, who used NES, were more likely to be placed at work and being sustained with the new employer. So, this may be an argument to use this as an indicator to allocate injured workers into OES or NES services. The negative impact of mental health issues on employment [18] and timely RTW [19] has been reported in the literature. However, our study shows that injured workers with mental issues do not always have lower RTW rate. They just need special consideration. If they commence their OR services in NES initiative, they can achieve better outcomes.

\section{Strengths and limitations}

The main strength of this study is to use a well-structured and population-based dataset. This study provides a comprehensive analysis on the likelihood of RTW and sustainability for OR users by using four groups of predictors. Analyses result in understandings on substantial factors influencing the outcomes of OR initiatives. In addition, the results refer to insightful conclusion regarding mental health.

The main limitation of this study is that the data we used is for injured workers in Victoria state in Australia. So, the results are more valid for this group of patients. Another limitation of this study is to use administrative data. We used wage compensation in payment data as a proxy to define RTW and sustainability.

\section{Conclusion}

In this study, a comprehensive investigation of using OR services (preparation for RTW) for work-related injured patients was performed regarding desired outcomes (RTW and sustaining at work). The association of four groups of 
predictors with outcomes has been analysed. These groups are claimant characteristics, injury characteristics, employment characteristics and claim management that include 13 predictors. This paper provides a complete descriptive analysis of OR services performance, a variety of statistical techniques are applied to prove that observed positive changes are statistically significant and we presented analytical models that have examined the impact of multiple predictors on the observed outcomes, and an insight into risk factors which are associated with the outcomes.

The analytical results show that the group of predictors that were mostly associated with OES outcomes were injury characteristics, e.g. use of psychiatric services, type of injury and hospital admissions, while the most significant predictors for NES outcomes were not injury related, e.g. age, occupation and time to NES services commencement. The analysis on predictors associated with OR outcomes provides insight for WSV to develop practices that are best suitable to individuals. For example, using psychiatric services is an important factor for OES outcomes. So, agents can provide customised services for these clients. The analysis also demonstrates that workers with mental injuries were less likely to achieve RTW and have a sustained RTW through OES compared to injured workers with other types of injuries. Whereas, it is a different story for NES users i.e. workers with mental injuries were more likely to have RTW and sustain at work through the NES services. We conclude that workers with mental injuries are not necessarily workers with the least likelihood for RTW, instead they are less likely to return at their previous workplace.

Acknowledgments This study is funded by WorkSafe Victoria (WSV) through the Institute of Safety, Compensation and Recovery Research (ISCRR). ISCRR is a joint initiative of WorkSafe Victoria, the Transport Accident Commission (TAC) and Monash University.

Funding This study is funded by WorkSafe Victoria (WSV) through the Institute of Safety, Compensation and Recovery Research (ISCRR).

Compliance with Ethical Standards

Conflict of interest Hadi Akbarzadeh Khorshidi, Miriam Marembo and Uwe Aickelin declare that they have no conflict of interest.

Ethical Approval This article does not contain any studies with human participants performed by any of the authors.

Informed Consent Statement not required. This study was performed using a de-identified administrative dataset, with ethics approval granted by Monash University Human Research Ethics Committee (CF09/3150 - 2009001727).

\section{References}

1. Berecki-Gisolf J, Collie A, McClure RJ. Determinants of physical therapy use by compensated workers with musculoskeletal disorders. Journal of Occupational Rehabilitation. 2013;23(1):63-73.

2. Pransky G, Gatchel R, Linton SJ, Loisel P. Improving return to work research. Journal of Occupational Rehabilitation. 2005;15(4):453-7.

3. Brouwer S, Franche RL, Hogg-Johnson S, Lee H, Krause N, Shaw WS. Return-to-work self-efficacy: Development and validation of a scale in claimants with musculoskeletal disorders. Journal of Occupational Rehabilitation. 2011;21(2):244-58.

4. Park J, Roberts MR, Esmail S, Rayani F, Norris CM, Gross DP. Validation of the Readiness for Return-To-Work Scale in Outpatient Occupational Rehabilitation in Canada. Journal of Occupational Rehabilitation. 2018;28(2):332-45.

5. Franche RL, Krause N. Readiness for return to work following injury or illness: Conceptualizing the interpersonal impact of health care, workplace, and insurance factors. Journal of Occupational Rehabilitation. 2002;12(4):233-56.

6. Awang H, Mansor N. Predicting Employment Status of Injured Workers Following a Case Management Intervention. Safety and Health at Work. 2017.

7. Berecki-Gisolf J, Clay FJ, Collie A, McClure RJ. Predictors of sustained return to work after work-related injury or disease: Insights from workers' compensation claims records. Journal of Occupational Rehabilitation. 2012;22(3):283-91.

8. Gray SE, Hassani-Mahmooei B, Cameron ID, Kendall E, Kenardy J, Collie A. Patterns and Predictors of Failed and Sustained Return-to-Work in Transport Injury Insurance Claimants. Journal of Occupational Rehabilitation. 2018:1-9. 
9. Prang KH, Hassani-Mahmooei B, Collie A. Compensation Research Database: population-based injury data for surveillance, linkage and mining. BMC Research Notes. 2016;9(1):1-11.

10. Hou W-H, Chi C-C, Lo H-L, Chou Y-Y, Kuo KN, Chuang H-Y. Vocational rehabilitation for enhancing returnto-work in workers with traumatic upper limb injuries. Cochrane Database of Systematic Reviews. 2017(12).

11. Athanasou JA. A Vocational Rehabilitation Index and Return to Work after Compensable Occupational Injuries in Australia. Australian Journal of Rehabilitation Counselling. 2017;23(2):69-78.

12. Lingard H, Saunders A. Occupational rehabilitation in the construction industry of Victoria. Construction Management and Economics. 2004;22(10):1091-101.

13. Collins GS, Reitsma JB, Altman DG, Moons KGM. Transparent reporting of a multivariable prediction model for individual prognosis or diagnosis (TRIPOD): the TRIPOD Statement. BMC Medicine. 2015;13(1):1.

14. Gray SE, Hassani-Mahmooei B, Kendall E, Cameron ID, Kenardy J, Collie A. Factors associated with graduated return to work following injury in a road traffic crash. Journal of Transport \& Health. 2018;10:167-77.

15. Steyerberg EW, Harrell FE, Borsboom GJJM, Eijkemans MJC, Vergouwe Y, Habbema JDF. Internal validation of predictive models: Efficiency of some procedures for logistic regression analysis. Journal of Clinical Epidemiology. 2001;54(8):774-81.

16. Delen D, Fuller C, McCann C, Ray D. Analysis of healthcare coverage: A data mining approach. Expert Systems with Applications. 2009;36(2 PART 1):995-1003.

17. James G, Witten D, Hastie T, Tibshirani R. An Introduction to Statistical Learning: with Applications in R: Springer-Verlag New York; 2013.

18. Frijters P, Johnston DW, Shields MA. The effect of mental health on employment: Evidence from australian panel data. Health Economics (United Kingdom). 2014;23(9):1058-71.

19. Brijnath B, Mazza D, Singh N, Kosny A, Ruseckaite R, Collie A. Mental Health Claims Management and Return to Work: Qualitative Insights from Melbourne, Australia. Journal of Occupational Rehabilitation. 2014;24(4):766-76.

\section{Appendix}

\begin{tabular}{|l|l|l|}
\hline \multicolumn{2}{|l|}{ Title and abstract } & Our paper includes title which reflect the study and the main results. \\
\hline 1 & Title & $\begin{array}{l}\text { Our paper includes abstract which provides a summary of objectives, study } \\
\text { design, setting, participants, predictors, outcomes, statistical analysis, results } \\
\text { and conclusions. }\end{array}$ \\
\hline 2 & Abstract & \multicolumn{2}{|l|}{} \\
\hline \multicolumn{2}{|l|}{ Introduction } & $\begin{array}{l}\text { Our paper specifies the objectives and modeling. It also explains the rationale } \\
\text { behind the study and includes references to existing models. }\end{array}$ \\
\hline 3 & Background and objectives \\
\hline Methods & Our paper describes the source of data and specifies the key dates. \\
\hline 4 & Source of data & $\begin{array}{l}\text { Our paper specifies the study setting and describes selection criteria for } \\
\text { participants. }\end{array}$ \\
\hline 5 & Participants & Our paper defines the outcomes that are going to be predicted. \\
\hline 6 & Outcome & Our paper clearly defines all predictors used in the model. \\
\hline 7 & Predictors & $\begin{array}{l}\text { Our paper clearly mentions the sample size and explains how we arrived at } \\
\text { this size. }\end{array}$ \\
\hline 8 & Sample size & We did not have missing data. \\
\hline 9 & Missing data & $\begin{array}{l}\text { Our paper describes predictor handling in analyses, modelling procedures, } \\
\text { measures for model assessment and how to update the model due to } \\
\text { multicollinearity. }\end{array}$ \\
\hline 10 & Statistical analysis methods \\
\hline 11 & Risk groups & We did not have any risk group in our study. \\
\hline 12 & Development vs validation & Our paper identifies the claims with multiple commencements in the data set. \\
\hline Results & \multicolumn{2}{|l|}{} \\
\hline 13 & Participants & $\begin{array}{l}\text { Our paper includes descriptive statistics about participants. } \\
\text { the association between predictors and outcomes. }\end{array}$ \\
\hline 14 & Model development & $\begin{array}{l}\text { Our paper presents the full prediction models including all odds ratios and } \\
\text { baselines. }\end{array}$ \\
\hline 15 & Model specification &
\end{tabular}




\begin{tabular}{|c|c|c|}
\hline 16 & Model performance & Our paper reports performance measures for prediction models. \\
\hline 17 & Model updating & $\begin{array}{l}\text { Our paper reports how the prediction models are updated due to } \\
\text { multicollinearity. }\end{array}$ \\
\hline \multicolumn{3}{|c|}{ Discussion } \\
\hline 18 & Limitations & Our paper discusses strengths and limitations of the study. \\
\hline 19 & Interpretation & $\begin{array}{l}\text { Our paper provides conclusion and interpretation of results considering } \\
\text { objectives. }\end{array}$ \\
\hline 20 & Implications & $\begin{array}{l}\text { Our paper discusses how the results provide insights for decision makers and } \\
\text { service providers to improve the processes. }\end{array}$ \\
\hline \multicolumn{3}{|c|}{ Other information } \\
\hline 21 & Supplementary information & Our paper provides information about ethics related to data set. \\
\hline 22 & Funding & Our paper acknowledges the source of funding for the study. \\
\hline
\end{tabular}

